\title{
Incorporating Intelligence into Exit Choice Model for Typical Evacuation
}

(Penggabungan Kecerdasan kepada Model Pilihan Keluar untuk Pemindahan Tipikal)

\author{
MOHAMMED SHUAIB* \& ZARITA ZAINUDDIN
}

\begin{abstract}
Integrating an exit choice model into a microscopic crowd dynamics model is an essential approach for obtaining more efficient evacuation model. We describe various aspects of decision-making capability of an existing rule-based exit choice model for evacuation processes. In simulations, however, the simulated evacuees clogging at exits have behaved non-intelligently, namely they do not give up their exits for better ones for safer egress. We refine the model to endow the individuals with the ability to leave their exits due to dynamic changes by modifying the model of their excitement resulted from the source of panic. This facilitates the approximately equal crowd size at exits for being until the end of the evacuation process, and thereby the model accomplishes more optimal evacuation. For further intelligence, we introduce the prediction factor that enables higher probability of equally distributing evacuees at exits. A simulation to validate the contribution is performed, and the results are analyzed and compared with the original model.
\end{abstract}

Keywords: Decision making; evacuation; exit choice; prediction

\section{ABSTRAK}

Mengintegrasikan model pilihan keluar kepada model dinamik mikroskopik ramai adalah pendekatan penting untuk mendapatkan model pemindahan yang lebih cekap. Kami menerangkan pelbagai aspek keupayaan membuat keputusan bagi model pilihan keluar berasaskan peraturan sedia ada untuk proses pemindahan. Namun, dalam simulasi, mangsa yang dipindahkan tersangkut di pintu keluar telah bertindak tidak bijak, iaitu mereka tetap dengan jalan keluar mereka tanpa mendapatkan jalan keluar yang lebih selamat. Kami memperbaiki model untuk memberikan individu keupayaan untuk keluar disebabkan oleh perubahan dinamik dengan mengubah model keterujaan mereka yang dihasilkan daripada sumber panik. Ini memudahkan orang ramai di pintu keluar sehingga proses pemindahan berakhir dan dengan demikian model itu dapat melakukan pemindahan lebih optimum. Untuk kecerdasan lanjut, kami memperkenalkan faktor ramalan yang membolehkan kebarangkalian yang lebih tinggi untuk sama-sama mengagihkan mangsa di pintu keluar. Satu simulasi untuk pengesahan sumbangan dijalankan dan keputusan dianalisis dan dibandingkan dengan model asal.

Kata kunci: Membuat keputusan; pemindahan; pilihan keluar; ramalan

\section{INTRODUCTION}

In emergency situations, massive congestion has resulted in disasters and crowd stampedes, resulting in injuries and loss of lives (Elliott et al. 1993; Keating 1982; Mydans 2009). The psychological, social and political effects of a crowd disaster - despite being relatively rare and with limited deaths - have been significant (Hills 1998; Sime 1999). Empirical studies indicated that disorder and blocking at egresses by the panicked evacuees are critical reasons affect the safe evacuation as well as increase the total evacuation time (Bohannon 2005). Therefore, researchers have been motivated to make concerted efforts in order to prevent the emergence of such factors by offering better pedestrian facilities and understanding the behaviors of pedestrians to eliminate the undesirable behaviors. Accordingly, researchers have devoted much effort to modify the models for exit choice, which is an essential decision-making aspect in the evacuation process. In these models, several approaches have been proposed by incorporating psychological rules based on psycho- architecture studies (Canter 1985; Passini 1984; Proulx 1993). Considering these rules, modifying microscopic models to take into account the aspects of the evacuation process has been accomplished by many researchers. In the Cellular Automata Simulation model, for example, the introduction of the floor field which provides individuals with minimum intelligence (Burstedde et al. 2001) has helped introduce simulations for evacuation process in large rooms. Zhang et al. (2014) proposed a multi-agent based evacuation model, in which the action direction of each agent is affected by the distance of the agent to the exits and the occupant number and density within the view field of the agent. Wang et al. (2015a) modified the model by incorporating panic behavior to include emergency situations.-

On the other hand, independent exit choice models have been incorporated into microscopic models. Among of which are applied to the Cellular Automata Simulation model such as game-theory based models (Ehtamo et al 2008; Lo et al. 2006); logit-based discrete choice model 
(Guo \& Huang 2010; Huang \& Guo 2008) and extended dynamic communication field (DCF) model (Wang et al. 2015b; Wang et al. 2015c), on which the transmission process of escape information and its function on the evacuees' movement are presented. Other exit choice models integrated with the Social Force Model are the macroscopic network-flow model established by Luh et al. (2012) to help improve evacuees' survivability and egress efficiency. Zainuddin and Shuaib $(2011,2010)$ developed a rule based exit choice model (ZM model), where decisionmaking aspects have been incorporated for emergency and non-emergency situations.

Regarding the aforementioned literature stated, there is still a need of incorporating aspects of human intelligence, in the behavioral level of the pedestrians that help involve more real aspects of choosing exits and routes. In this article, for optimal evacuation process that could obtain safe evacuation and prevent disorder and blocking at exits, we modify the ZM model by incorporating further intelligence capability to be provided for the simulated individuals. Namely, the aspect of intelligence that the individuals leave their exits for safer egress due to dynamic changes in the evacuation process is incorporated. Furthermore, a modification of the assessment process of individuals assessing their environment is made by incorporating the capability of predicting crowds at the perceived exits. Therefore, the individuals are provided with the ability to choose the most proper exits for their evacuations with less probability to change these exits. The organization of this article is as follows. In section two, a brief introduction of the Social Force Model and the decision-making aspects incorporated into the model for the evacuation process are introduced in the first subsection. In the second subsection, decision making aspects in the ZM Model are explained. In the third section, the ZM model is modified. In section four, simulations to trace the qualitative behavior of simulated pedestrians corresponding to the above contributions are performed, and analyses of the results to be compared with the original model are made.

\section{THE SOCIAL ForCE MODEL AND DECISION- MAKING CAPABILITY}

\section{THE SOCIAL FORCE MODEL}

The social force model (denoted here by SFM) is proposed by Helbing and Molnar (1995). The pedestrians in the SFM are self-driven particles. The most important feature is that the representation of pedestrian's motivations exerted by the objects surrounding him (pedestrians and obstacles) as social forces. The sum of these forces is implemented in a Newtonian equation, which leads to acceleration to the pedestrian's motion. An extension by Helbing et al. (2000) incorporated the physical forces (pushing and friction) into the model. These forces arise in case of contact occurring among the pedestrians. The main equations of the model are

$$
\begin{aligned}
& \frac{d \vec{x}_{i}(t)}{d t}=\vec{v}_{i}(t), \\
& m_{i} \frac{d \vec{v}_{i}(t)}{d t}=\vec{f}_{i}^{\text {pref }}(t)+\sum_{j} \vec{f}_{i j}^{\text {social }}(t)+\sum_{j} \vec{f}_{i j}^{\text {physical }}(t)+\varepsilon_{i}(t)
\end{aligned}
$$

where $\frac{d \vec{x}_{i}(t)}{d t}$ is the rate of change of the location of pedestrian $i ; d \vec{v}_{i} / d t$ is his acceleration resulting from the sum of total forces upon him; $\varepsilon_{i}(t)$ is the fluctuation term; the function $\vec{f}_{i}^{\text {pref }}(t)$ is the preferred force modeled to express the motivation inside the pedestrian to adapt his actual velocity $\vec{v}_{i}(t)$ to reach his preferred velocity $\vec{v}_{i}^{0}=V_{i} \vec{e}_{i}^{0}(t)$ at which he prefers to walk as follows:

$$
\vec{f}_{i}^{\text {pref }}(t)=m_{i} / \tau\left(V_{i} \vec{e}_{i}^{0}(t)-\vec{v}_{i}(t)\right)
$$

where $\vec{e}_{i}^{0}(t)$ is the preferred direction of pedestrian $i$ at time $t ; V_{t}$ is his preferred speed; and $m_{i}$ and $\tau$ represent the mass of the pedestrian $i$ and the relaxation time, respectively.

The social forces $\vec{f}_{i j}^{\text {social }}$ are of two types: the repulsion force $\vec{f}_{i j}^{r e p}(t)$ which represents the model of the repulsive motivation inside pedestrian $i$ to avoid pedestrian $j$ and the attraction force $\vec{f}_{i j}^{\text {att }}(t)$ which represents the model of the attractive motivation inside pedestrian $i$ toward pedestrian $j$ (Helbing \& Molnár 1995). The forces of the SFM are characterized with parameters capable to be formulated to accommodate enormous aspects of crowd dynamics to introduce self-organization phenomena (Helbing et al. 2002; Lakoba et al. 2005) to reproduce real life data (Shuaib 2014; Zainuddin \& Shuaib 2010b) and to control various walking behaviors such as walking competition (Shuaib 2014) and penetrating jammed crowd (Shuaib 2016).

The SFM has been modified for evacuation situations (Helbing et al. 2000) by incorporating physical forces that emerge in situations where contact exists. Incorporating the panic factor in Helbing et al. (2000) governs individuals' behaviors by adapting their speeds and their directions according to the given situation. Herding behavior is produced by the panic factor when the individuals are highly panicked. Analogous to the panic factor, Lakoba et al. (2005) proposed the excitement factor which has a rate of change proportional to the difference between the effective maximum excitement parameter $E_{m}(1-v(t) /$ $\left.v^{0}(t)\right)$ and the excitement parameter

$$
\frac{d E(t)}{d t}=\alpha\left(E_{m}\left(1-\frac{v(t)}{v^{o}(t)}\right)-E(t)\right) .
$$

The equations of the preferred velocity and its direction given in Lakoba et al. (2005) are

$$
\vec{v}_{i}^{0}(t)=\vec{e}_{i}^{0}(t) \cdot\left(1+E_{i}(t)\right) \cdot V^{0}
$$




\section{INTEGRATING EXIT CHOICE MODEL INTO THE SOCIAL FORCE MODEL}

Zainuddin and Shuaib $(2011,2010 a)$ have introduced an exit choice model (ZM model) by providing the independent individuals the ability of performing an assessment process of the current evacuation and then make a decision to choose an exit from a set of exits available in the physical environment. This established by accounting for the utility of each exit from the individual's perspective and then making a decision of choosing the exit that maximizes his ambition. The utility exit - value $_{i k}$ of an exitwas introduced in (Zainuddin \& Shuaib 2011) as a linear combination of the utilities of two factors: the design of the exit (design - effect ${ }_{k}$ ) and the distance between the individual $i$ and this exit $\left(\right.$ dist $^{-}$effect $\left._{i k}\right)$, governed by the excitement factor introduced in (4).

$$
\begin{aligned}
\operatorname{exit}_{-\operatorname{value}_{i k}(t)=} & \operatorname{design}-\operatorname{eff}(t) .\left(1-E_{i}(t)\right) \\
& +\operatorname{dist}_{-} \operatorname{effect}_{i k}(t) .\left(E_{i}(t)\right)
\end{aligned}
$$

Accordingly, if individual $i$ is highly excited, then the effect of the distance factor would be greater; if the excitement factor is low, then the individual would consider the design as a major determinant of the best exit for egress.

The factor design _effect $t_{k}$ is not concerned in this work ((Xiao et al. 2016) as an example for the test and analysis of the design factor). The model of dist_effect $t_{i k}$ was refined in (Zainuddin \& Shuaib 2010) to incorporate the impact of clogging crowd at the perceived exits and it is introduced as follows:

$$
\begin{aligned}
\text { dist_eff } i, k & (t)=\exp \left[-l_{i} \cdot\left(d_{i, r_{k}}(t)\right) \cdot E_{i}(t)\right] \cdot\left(1-\alpha_{i}\left(\frac{r_{k}(t)}{r_{\max }(t)}\right)^{\beta_{i}}\right) \omega\left(\phi_{i k}(t)\right) \\
\omega\left(\phi_{i k}(t)\right) & =\left(\begin{array}{cc}
1 & \left|\phi_{i k}(t)\right| \leq \frac{\pi}{2}+\frac{\pi}{2} \cdot\left(1-E_{i}(t)\right) \\
0 & \text { otherwise }
\end{array}\right),
\end{aligned}
$$

where $r_{k}$ is the radius of the crowded area of exit k; and $d_{i, t_{k}}$ is the distance between the location of individual $i$ and the circumference of this crowded area. The function $\omega\left(\phi_{i k}\right)$ is used to consider the perception of the individual i for the exits with respect to his excitement.

At each time step $t_{\text {decision }}$ that is assumed for the simple reaction time of the assessment process, the individual $i$ may make a decision $\left(D S_{\text {change }}, i=1\right)$ to replace his current preferred direction $\vec{e}_{\text {curr }, i}^{0}$ with new direction toward the exit. This is achieved when the new direction acquired maximum utility that is higher than the utility of the current chosen exit with worthwhile magnitude as follows:

$$
\text { best_exit } t_{i}\left(t_{\text {decision }}\right)=\operatorname{index}\left\{\max _{k}\left(\text { exit_value }{ }_{i k}\left(t_{\text {decision }}\right)\right)\right\}
$$

$$
\vec{e}_{\text {curr }, i}^{0}\left(t_{\text {decision }}\right)=\left\{\begin{array}{cc}
\vec{e}_{\text {best_exit }}^{0}\left(t_{\text {decision }}\right) & D S_{\text {change }, i}=1 \\
\vec{e}_{\text {curr }, i}^{0}\left(t_{\text {deision }}\right) & D S_{\text {change }, i}=0 .
\end{array}\right.
$$

The equations of the preferred velocity and direction $\vec{e}_{i}^{0}$ for the whole individuals were given in the ZM Model by,

$$
\vec{v}_{i}^{0}(t)=\vec{e}_{c u r, i}^{0}(t)\left(1+E_{i}(t)\right) V_{i}^{0}
$$

\section{MODIFICATION OF ZM MODEL FOR EVACUATION PROCESS}

\section{PROBLEMATIC ISSUES}

For the purpose of calibration, we have performed simulations based on the ZM exit choice model in emergency situations, where the environment is a room with three exits (Figure1). By investigating the crowd behavior, it has been found that there is mostly dissimilar equal crowd size at exits. Moreover, coincident termination of the evacuation process at those exits could hardly be achieved (the graphical representation of the evacuation time is introduced in Figure 1).

We impose two factors as reasons for the occurrence of asymmetric crowd size at exits in ZM simulations. Firstly, the first decision made by the simulated individual for his evacuation is selecting an exit k only based on the uncongested distance $d_{i, \text { unicorn_k }}(7)$, where there is no crowd at exits $\left(r_{k}=0\right)$ within the beginning time of the corresponding simulations. According to (7), the simulated individual does not predict clogging at his chosen exit, although the presence of other individuals who were closer to these exits and fleeing in the same direction. Thereby, the constituted crowd size initially formed at exits would be based mainly on the location distribution of the individuals in the physical environment (i.e. the initialization of their locations as shown in Figure 2).

The second reason is the adherence to exits. We determined that the excitement factor in dist_eff $f_{i k}$ (7) plays the primary role that does not help the individuals to give up in changing their exits. When the individual joins a crowd at an exit, his velocity becomes lower. According to (4), the concerned individual becomes highly excited, causing high dropping in the curvature of distance utility of the farthest away exits. Thus, the individual would be unlikely to leave his current exit. Regarding intelligence, dissimilar crowd size at exits is expected to be adapted because reasonable and intelligent individuals would investigate the situation and make decisions to move from crowded exits to less crowded ones to achieve their goals, namely, fleeing from the simulated room and reducing evacuation times. For this reason, we propose in the next section a modification for the ZM model to achieve almost equal crowd size at the perceived exits to obtain simultaneous termination of the evacuation process. 


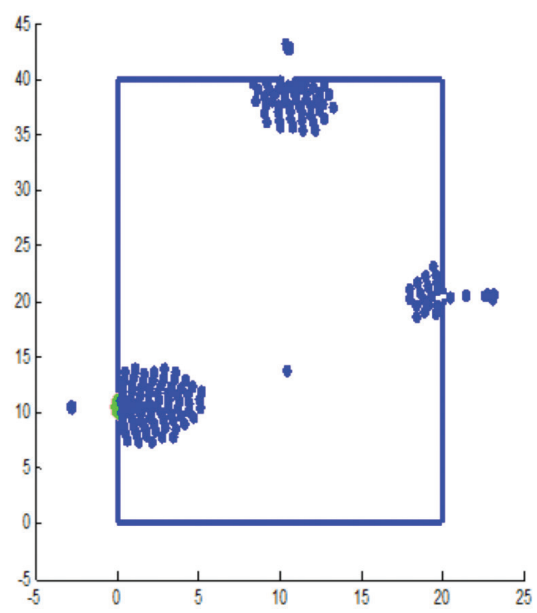

(a)

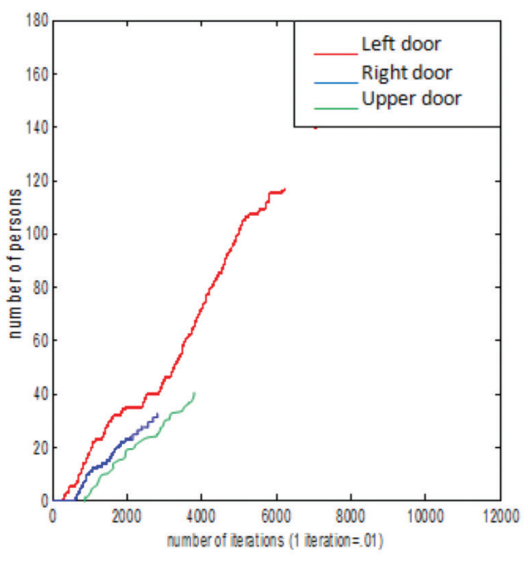

(b)

FIGURE 1. (a) A snapshot from a simulation based on the ZM exit choice model and (b) A diagram that includes three curves to show the evacuated at each exit with respect to the physical time, where one iteration is $.01 \mathrm{~s}$. The elapsed time is $270.379000 \mathrm{~s}$

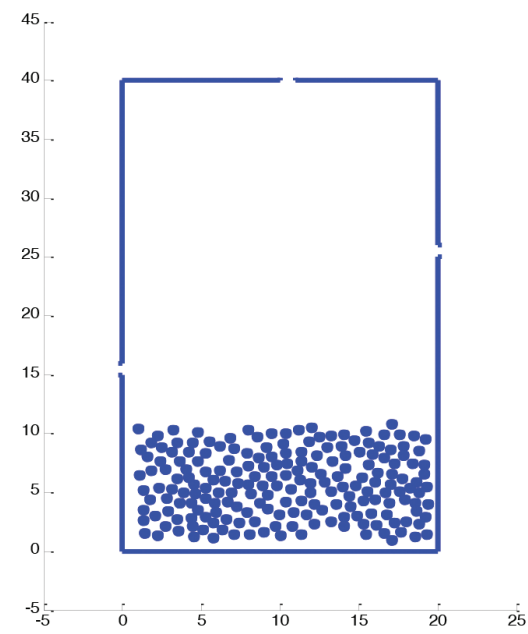

(a)

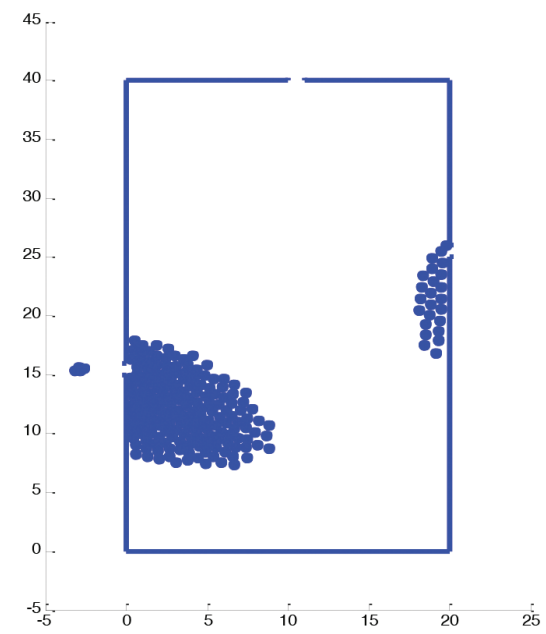

(b)

FIGURE 2. Snapshots from the simulation based on the ZM exit choice model, (a) the locations of the individuals were initialized and (b) the individuals made new decisions toward the left and right exits. The decisions were only based on the distance factor

\section{REFINEMENT OF ZM MODEL FOR EVACUATION PROCESS}

In this subsection we replace the excitement factor with another factor to enable the individuals leaving their exits for better evacuation, and then we incorporate a prediction characteristic to be provided to the individuals as an aspect of intelligence.

\section{INCORPORATING THE RUSH PARAMETER}

Our work here introduces the rush factor to involve the individual's assessment with respect to the threat of the source of panic. The major role of the rush parameter is to connect the individual's assessment with his preferred velocity instead of his actual velocity, where the former is representative of the exit threat. We consider unmoving source of panic in the emergency situation. The individual would first acquire an initial value of preferred velocity corresponding to his evaluation of the threat of this source of panic as follows. If there is no source of panic, then the individual prefers to walk in his normal velocity. If the source of panic causes extreme aversion, then the individual would prefer to flee in his max velocity. This model of the rush factor is represented by

$$
R u s h_{i}=\frac{v_{i}^{0}-w_{i}^{0}}{v_{i}^{\max }-w_{i}^{0}} .
$$

where $w_{i}^{0}$ is the actual velocity of an individual walking in normal situation, as measured empirically. The rush parameter is incorporated in (7) instead of the excitement parameter as follows:

$$
\begin{aligned}
d i s t_{-} e f f_{i, k}(t)= & \exp \left[-l_{i} \cdot\left(d_{i, r_{k}}(t)\right) \cdot \operatorname{Rush}_{i}(t)\right] . \\
& \left(1-\alpha_{i}\left(\frac{r_{k}(t)}{r_{\max }(t)}\right)^{\beta_{i}}\right) \omega\left(\phi_{i k}(t)\right)
\end{aligned}
$$


By this formulation, the assessment of an individual would not be affected by the reduction of his actual velocity.

\section{INCORPORATING PREDICTION FACTOR FOR THE INDEPENDENT INDIVIDUALS}

We consider situations where the fleeing individuals are sufficiently conscious to use their intelligence while fleeing from their physical environment. Reasonably, we can assume that they can predict the future situation of their chosen exits; they can count the other individuals fleeing toward an exit $\mathrm{k}$ with the clogging individuals in the formed crowd at this exit before joining this crowd, then the individual can make a decision based on this prediction. Equation (7) was formulated in terms of the radius $r_{k}$ of the crowded area of exit $\mathrm{k}$ and the distance $d_{i, \text { unicon_k }}$ between the location of individual $i$ and the circumference of this area. For the purpose of refinement, we re-express this radius factor $\sigma_{k}$ in terms of number of individuals as follows.

Based on the equation of the density in a semi-circle area $\mathrm{k}$,

$$
\sigma_{k}=\frac{2 \cdot n_{k}^{c \log g}}{\pi \cdot r_{k}^{2}},
$$

where $n_{k}^{\operatorname{cog} g}$ is the number of the individuals who form the crowd at exit $\mathrm{k}$. We induce a relationship to express the radius of this area in terms of the number of pedestrians $n_{k}^{c \log g}$ and the density $\sigma_{k}$ of this area as follows:

$$
r_{k}=\sqrt{\frac{2 \cdot n_{k}^{c \log g}}{\pi \cdot \sigma_{k}}}
$$

Accordingly, based on the assumption stated in (Zainuddin \& Shuaib 2010a) that $\sigma_{k}=\sigma_{\max } \forall$ exit $k$, we obtain the following relationship:

$$
\frac{r_{k}}{r^{\max }}=\left(\frac{n_{k}^{\operatorname{cog} g}}{N^{\max }}\right)
$$

where $r^{\max }, N^{\max }$ are the radius and the number of the individuals within the highest crowded semi-circle area among the crowded areas of the available exits, respectively. Thus (8) becomes

$$
\begin{aligned}
\text { dist_eff }_{i, k}(t)= & \exp \left[-l_{i \cdot}\left(D_{i, k}(t)-\sqrt{\frac{2 \cdot n_{k}^{c \operatorname{cog} g}(t)}{\pi \cdot \sigma_{k}}}\right) \cdot E_{i}(t)\right] . \\
& \left(1-\alpha_{i}\left(\frac{n_{k}^{\operatorname{cog} g}(t)}{N^{\max }(t)}\right)^{\beta_{i}}\right)
\end{aligned}
$$

where $D_{i, k}$ is the total distance between the location of individual $i$ and the center of exit $\mathrm{k}$.

To incorporate the prediction ability of an individual, it is sufficient to add the fleeing individuals toward the targeted exit with the number of individuals clogging this exit. The equation of the new model becomes

$$
\begin{aligned}
& \text { dist_eff } f_{i, k}(t)=\exp \left[-l_{i} \cdot\left(D_{i, k}-\sqrt{\frac{2\left(n_{k}^{\operatorname{cog} g}(t)+n_{i, k}^{\text {pred }}(t)\right)}{\pi \cdot \sigma_{k}}}\right) \cdot E_{i}(t)\right] \\
& \left(1-\alpha_{i}\left(\frac{n_{k}^{\text {clogg }}(t)+n_{i, k}^{\text {pred }}(t)}{N^{\max }(t)}\right)^{\beta_{i}}\right), \\
& n_{i, k}^{\text {pred }}(t)=\sum_{j} \mu_{i, k}^{j}(t),
\end{aligned}
$$

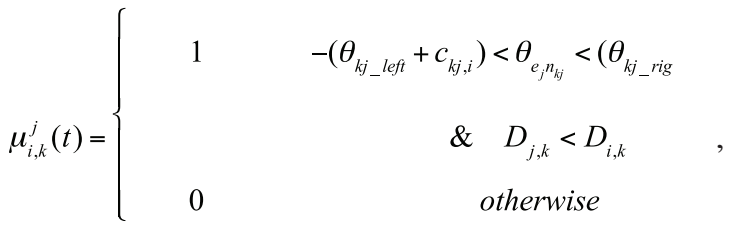

where $\mathrm{k}$ is the index of available exits, which are perceived by the fleeing individuals; $\mu_{i, k}^{j}(t)$ denotes the value of individual $\mathrm{j}$ associated to individual $i$ with respect to exit $\mathrm{k} ; \theta_{\vec{e} \cdot \vec{n}_{i}}$ is the angle between the direction of motion of individual $j\left(\vec{e}_{j}\right)$ and the vector pointing from him to the center of exit $\mathrm{k}\left(\vec{n}_{k j}\right) ; \theta_{k j \text { right }}$ and $\theta_{k j \text { left }}$ are the angles created by the vector $\vec{n}_{k j}$ and the other two vectors pointing from individual $j$ to the left and right endpoints of the exit, respectively. The angles $c_{k j \_l e f, i}$ and $c_{k j}$ right,i are two additional dynamic angles to determine perspective of individual $i$ in assessing the other individuals' directions toward exit $k$. The sum of the areas created by the angles $\theta_{k j \_r i g h t}, \theta_{k j \_l e f}, c_{k j}$ right,i and $c_{k j \text { lef }, i}$ comprises the dynamic area $A_{k}$, according to the design of exit $\mathrm{k}$ and the location of individual $i$ (the shadowed area in Figure 3). From the perspective of individual $i$, if the direction $\left(\vec{e}_{j}\right)$ of individual $j$ is within area $A_{k}$ and he is closer to exit k than individual $i$, then individual $j$ is considered to direct his motion toward exit $k$ and accordingly, $\mu_{i, k}^{j}(t)=1$.

\section{SiMULATION, RESULTS AND DISCUSSION}

\section{SIMULATION}

The simulation has been performed for a crowd exposed to a source of panic in a hall which has three exits. The dimensions of the hall are $20 \mathrm{~m}$ width and $40 \mathrm{~m}$ length and the exits are located at different positions, but have similar characteristics to help assess the role of the incorporated factors, as depicted in Figure 4(a). The location of the 200 simulated individuals are initialized randomly in the lower half part of the hall, and the unmoving source of panic is initialized at the lower wall. The situation of interest is evacuation where the individuals intend to leave the room as quickly as possible corresponding to his preferred velocity. The common values of the parameters used in the simulation were estimated as in Table 1. 


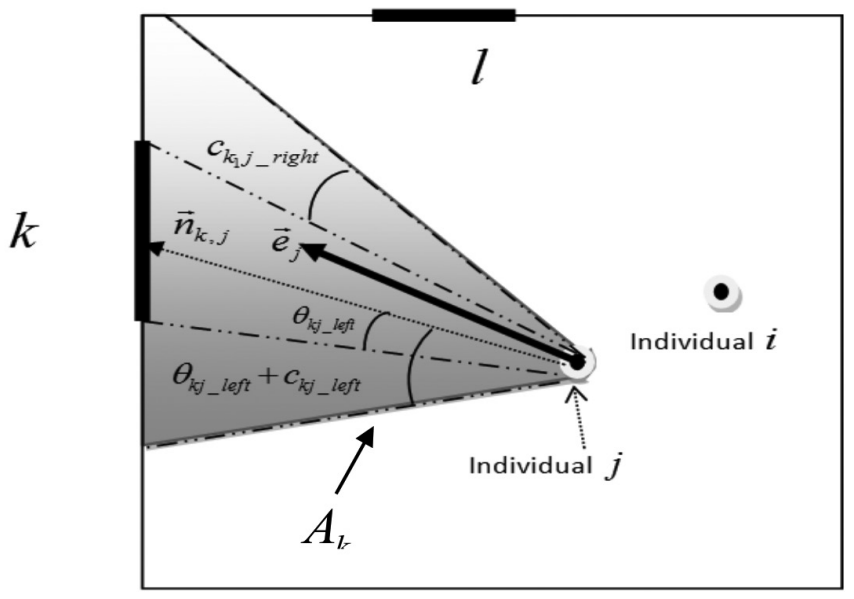

FIGURE 3. A physical environment with two exits $k, l$. Exit $k$ is associated with a shadowed area $A_{k}$ from the perspective of individual i to determine the direction $\vec{e}_{j}$ of individual $j$. Namely, if $A_{k}$ contains $\vec{e}_{j}$, then $\vec{e}_{j}$ would be considered as a direction toward $k$

TABLE 1 . The description and values of the parameters used in the simulation

\begin{tabular}{ll}
\hline The pedestrians' parameters: \\
\hline$m=[77-83] \mathrm{kg}$ & The pedestrians' mass: uniformly distributed within the range $(77-83) \mathrm{kg}$ \\
$r=[0.25-0.030] \mathrm{m}$ & The pedestrians' radius: uniformly distributed within the range $(0.25-0.30) \mathrm{m}$ \\
\hline The parameters of the social force model: \\
\hline$A^{\text {rep }}=2000 \mathrm{~N}$ & The strength of the repulsive social force \\
$B^{\text {rep }}=0.8$ & The characteristic distance of the repulsive force \\
$k=1.4 \times 10^{5} \mathrm{~kg} / \mathrm{sec}^{2}$ & The strength of the contact (pushing) force \\
$\kappa=2.4 \times 10^{5} \mathrm{kgm}^{-1} \mathrm{~s}^{-1}$ & The coefficient of the friction force \\
$V^{0}=3 \mathrm{~m} / \mathrm{s}$ & The initial preferred speed at the emerge of the source of panic \\
$\tau=0.5 \mathrm{~s}$ & The pedestrian reaction time \\
$\varepsilon \in\left[0,0.05^{*} v^{0} / \tau\right]$ & The fluctuation source of the pedestrian's acceleration is randomly assigned to each individual \\
\hline The parameters of extended model: \\
\hline$l=0.05$ & Constant parameter to capture the effect of distance \\
$\alpha=0.9$ & The strength of the repulsion of maximum radius \\
$\beta=1.5$ & Constant parameter to capture the curve of the radius-repulsion relation \\
$c_{k j}=\pi / 12$ & The perception angle determining the boundary of $A_{k}$ in Figure 4 \\
$\delta(k)=1$ & The environment contains targets in the second part of this section \\
\hline
\end{tabular}

\section{RESULTS AND DISCUSSION}

To show how the effect of prediction and rush factors will influence the distribution of the individuals at exits, we trace the behavior of the individuals, first by taking snapshots at the beginning of this simulation (the first decision made by the individuals) and then by taking other snapshots within the implementation to show the replicated decision making regarding the dynamic change of the crowd at exits.

The results deduced from the snapshots (Figure 4) are as follow. In Figure 4(a), the initialization of the individuals' locations allowed the individuals to direct their fleeing toward the left and right exits only. Accordingly, the individuals were divided into two equal-number groups directing their fleeing toward the left and right exits. The exclusion of the upper exit from the perceived exits was intended in this simulation, where the high value assigned to the distance parameter allows for this exclusion. In Figure 4(b), as the upper exit had appeared within the perception of the fleeing individuals, they were now able to make intelligent decisions by changing their direction toward the upper exit. In 4(c), similar crowd size at exits was obtained. It is worth noting here (as shown in Figure 4(d) and stated in Table 2) that the physical motion time in the modified model is less than the original, which indicates that using intelligence in making decisions leads to a safer evacuation. The reasons for the delay in the original model are asymmetric crowd size and high clogging at the first exit, which cause intermittent flow at this exit.

In case of the occurrence of intermittent flow in the modified model which might impair the obtained similar crowd size, it was noticed that some simulated individuals 


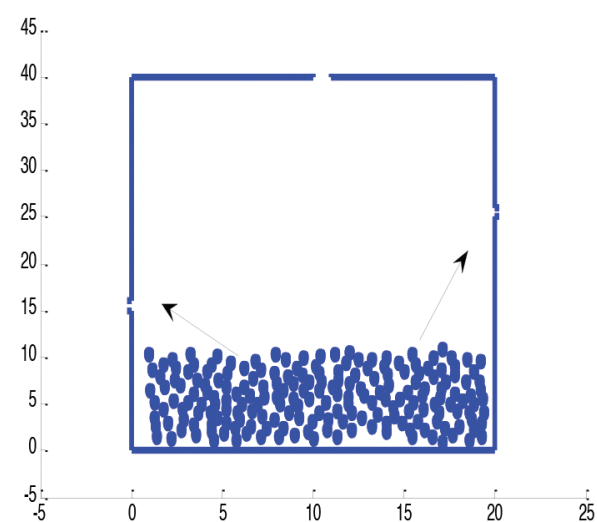

(a)

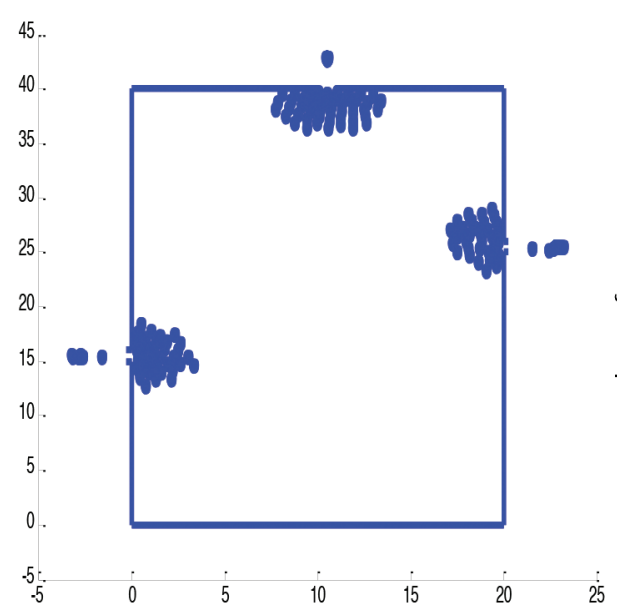

(c)

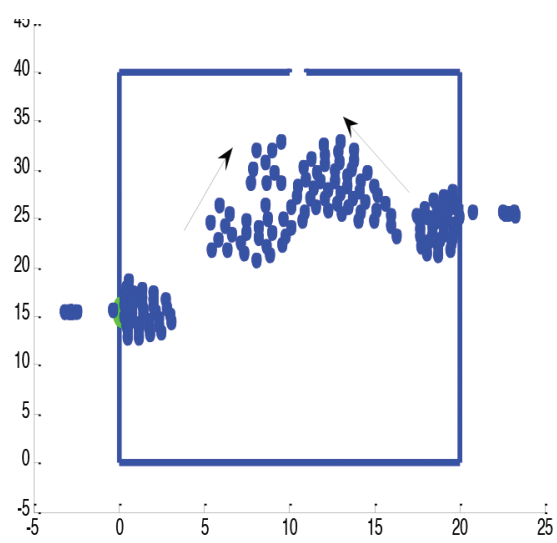

(b)

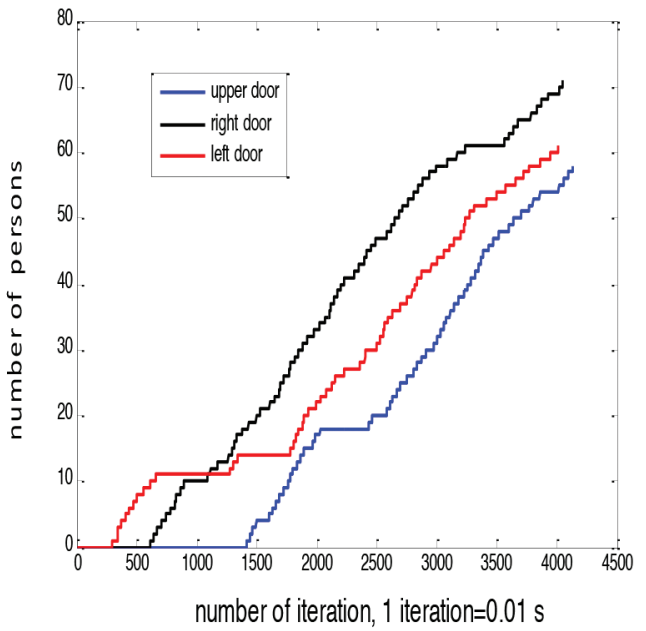

(d)

FIGURE 4. Snapshots from the simulation based on the modified ZM exit choice model. (a) the locations of the individuals were initialized, (b) the individuals made new decisions toward the third exit, (c) almost equal crowd size was obtained at the exits and (d) three curves are included to show the number of evacuated individuals verses the number of iterations, which represent the physical time of the evacuation process from the considered room

TABLE 2. The number of evacuated individuals at each exit based on the modified ZM model and the ZM Model

\begin{tabular}{lccc}
\hline & & $\begin{array}{c}\text { Simulation based on the } \\
\text { modified ZM Model }\end{array}$ & $\begin{array}{c}\text { Simulation based on the } \\
\text { ZM Model }\end{array}$ \\
\hline Exit 1 (left) & $\mathrm{P}$ & 61 & 119 \\
& $\mathrm{~T}$ & $40.0 \mathrm{~s}$ & $70.2 \mathrm{~s}$ \\
Exit 2 (right) & $\mathrm{P}$ & 71 & 35 \\
& $\mathrm{~T}$ & $40.4 \mathrm{~s}$ & $20 \mathrm{~s}$ \\
Exit 3 (up) & $\mathrm{P}$ & 58 & 41 \\
& $\mathrm{~T}$ & $41.2 \mathrm{~s}$ & $23 \mathrm{~s}$ \\
\hline
\end{tabular}

would rectify the situation in order to maintain the similar crowd size by leaving the highly crowded exit and directing their motion toward the less crowded exit. For further demonstration of the reformation process in the modified model, another simulation with identical specification of the first one was performed but with two exits. A comparison between the ZM model before and after the modification was made. The main different result is that, in the modified model, the individuals clogging at the left exit caused smooth flow to the upper exit as shown in Figure 5(a), which mainly resulted from the effect of the rush parameter. This flow would terminate after the approximate similar crowd size has been attained among the exits as shown in Figure $5(b)$. 


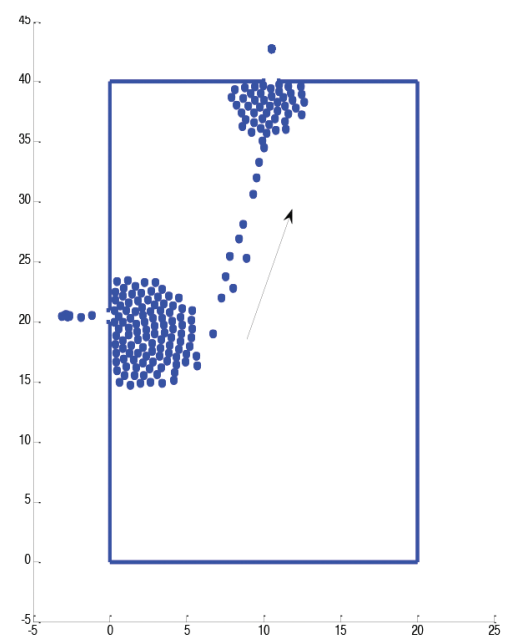

(a)

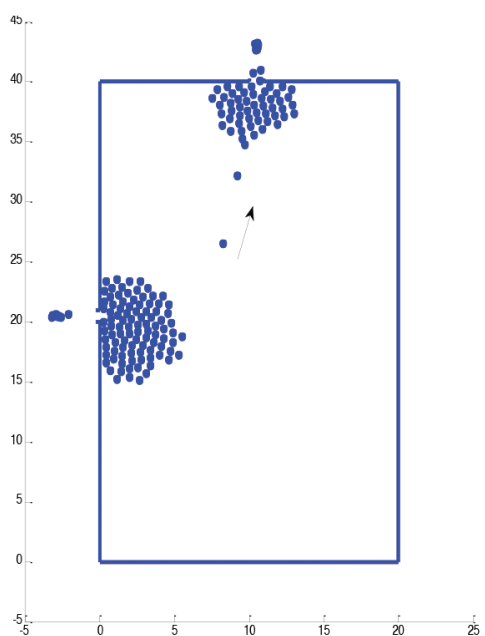

(b)

FIGURE 5. A simulation of a room with two exits to show the process of changing decision from one exit to another. This behavior is limited to achieving equal crowd size at the exits

\section{CONCLUSION}

In this article, to obtain equal crowd size at exits, prediction capability has been endowed to the simulated individuals by modeling the assessment process of the directions of others. Accordingly, the expected crowds at exits are computed initially and individuals' decisions are made based on this prediction. To conserve this almost equal crowd size, the excitement factor that is responsible for the adherence of individuals to their exits was replaced with the rush factor; the individual is thereby enabled to make quick decisions to achieve more utility from fleeing. As a result, almost equal crowd size at exits is more permanent. A simulation to show the aforementioned behaviors of individuals during the evacuation process has been performed. It is hoped that this work will be of particular benefit to those who are involved in the applications of microscopic studies.

\section{ACKNOWLEDGEMENTS}

We thank the Al-Imam Muhammad Ibn Saud Islamic University for supporting this work under the project No. 370807.

\section{REFERENCES}

Bohannon, J. 2005. Directing the herd: Crowds and the science of evacuation. Science 310(5746): 219.

Burstedde, C., Klauck, K., Schadschneider,A.\& Zittartz, J. 2001. Simulation of pedestrian dynamics using a two-dimensional cellular automaton. Physica A 295: 507-525.

Canter, D.V. 1985. Studies of human behavior in fire: Empirical results and their implications for education and design, Building Research Establishment Report, UK.

Ehtamo, H., Helïovaara, S., Hostikka, S. \& Korhonen, T. 2008. Modeling Evacuees' exit selection with best response dynamics. Proc. 4th Intl. Con.on Pedestrian and Evacuation Dynamics.p. 27.
Elliott, D., \& Smith, D. 1993. Football stadia disasters in the United Kingdom: learning from tragedy? Ind.Environ. Crisis Q7(3): 205-229.

Guo, R.Y. \& Huang, H.J. 2010. Logit-based exit choice model of evacuation in rooms with internal obstacles and multiple exits. Chin. Phys. B 19(3): 030501.

Huang, H.J. \& Guo, R.Y. 2008. Static floor field and exit choice for pedestrian evacuation in rooms with internal obstacles and multiple exits. Phys. Rev. E 78: Article ID. 021131.

Keating, J.P. 1982. The myth of panic. Fire J. 147: 57-61.

Helbing, D. \& Molnár, P. 1995. Social force model for pedestrian dynamics. Physical Review E 51: 4282-4286.

Helbing, D., Farkas, I. \& Vicsek, T. 2000. Simulating dynamical features of escape panic. Nature 407: 487-490.

Helbing, D., Farkas, I.J., Molnár, P. \& Vicsek, T. 2002. Simulation of pedestrian crowds in normal and evacuation situations. In Pedestrian and Evacuation Dynamics, edited by Schreckenberg, M. \& DeoSarma, S. Berlin: SpringerVerlag. pp. 21-58.

Hills, A. 1998. Seduced by recovery: The consequences of misunderstanding disaster. Journal of Contingencies and Crisis Management 6: 162-170.

Lakoba,T.I., Kaup, D.J. \& Finkelstein, N.M. 2005. Modifications of the Helbing-Molnar-Farkas-Vicsek Social Force Model for pedestrian evolution. Simulation 81: 339-352.

Lo, S.M., Huang, H.C., Wang, P. \& Yuen, K.K. 2006. A game theory based exit selection model for evacuation. Fire Safety J. 41: 364-396.

Luh, P., Wilkie, C. \& Chang, S. 2012. Modeling and optimization of building emergency evacuation considering blocking effects on crowd movement. IEEE Trans. Autom. Sci. Eng 9(4): 687-700.

Mydans, S. 2009. At least 59 die in Bangkok club fire. New York: New York Times. Accessed on 1st January 2009.

Passini, R. 1984. Wayfinding in architecture. Canada: Van Nostrand Reinhold Co.

Proulx, G. 1993. A stress model for people facing a fire. $J$. Environmental Psychology 13: 137-147.

Shuaib, M.M. 2016. Modeling the capability of penetrating jammed crowd to eliminate freezing transition. Chin. Phy. $B$ 25: 5 . 
Shuaib, M.M. 2014. Preserving socially expected crowd density in front of the exit for the reproduction of experimental data by modeling the pedestrians' behind perception. J. Stat. Mech: 10037.

Sime, J.D. 1999. Crowd facilities, management and communications in disasters. Facilities 17: 313-324.

Wang, X.L., Guo, W., Cheng, Y. \& Zheng, X.P. 2015a. Understanding the centripetal effect and evacuation efficiency of evacuation assistants: Using the extended dynamic communication field model. Safety Sci. 74: 150.

Wang, X.L., Guo, W. \& Zheng, X. 2015b. Effects of evacuation assistant's leading behavior on the evacuation efficiency: Information transmission approach. Chin. Phys. B 24(7): 070504.

Wang, J., Zhang, L., Shi, Q., Yang, P. \& Huc, X. 2015c. Modeling and simulating for congestion pedestrian evacuation with panic. Physica A 428: 396-409.

Xiao, S., Liang, M., Yaofei, M., Chen, Y. \& Hang, J. 2016. Selfishness- and selflessness-based models of pedestrian room evacuation. Physica A 447: 455-466.

Zainuddin, Z. \& Shuaib, M.M.A. 2011. Modeling the independence factor and its effect on the preferred force of the social force model in emergency and non-emergency situations. Appl. Math. Inf. Sci. 5(1): 53-64.

Zainuddin, Z. \& Shuaib, M. 2010. Modification of the decision making capability in the social force model for the evacuation process, Transport Theory and Statistical Physics 39: 1-24.
Zhang, L., Wang, J. \& Shi, Q. 2014. Multi-agent based modeling and simulating for evacuation process in stadium. J. Syst. Sci. Complex 27(3): 430-444.

Mohammed Shuaib*

College of Shari'a and Islamic Studies in Al Ahsaa

Department of Computer Sciences

Al-Imam Muhammad Ibn Saud Islamic University (IMSIU)

AlAhsaa 31982

Kingdom of Saudi Arabia

Zarita Zainuddin

School of Mathematical Sciences

Universiti Sains Malaysia

11800 USM, Penang, Pulau Pinang

Malaysia

*Corresponding author; email:mh_shuaib@yahoo.com

Received: 30 August 2016

Accepted: 13 February 2017 